\title{
Primary epithelioid angiosarcoma originating from the mandibular gingiva: a case report of an extremely rare oral lesion
}

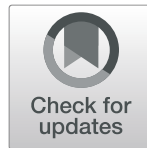

\author{
Yuko Komatsu ${ }^{1,2}$, Ikuya Miyamoto ${ }^{1,2^{*}}$ D, Yu Ohashi ${ }^{1,2}$, Katsunori Katagiri ${ }^{2,3}$, Daisuke Saito ${ }^{2,3}$, Mizuki Obara ${ }^{1,2}$, \\ Yasunori Takeda ${ }^{4}$, Kiyoto Shiga ${ }^{2,3}$ and Hiroyuki Yamada, ${ }^{1,2}$
}

\begin{abstract}
Background: Angiosarcoma occurs very rarely in the oral cavity, and the epithelioid type is even rarer. Here, we report a rare case involving an elderly man with a primary epithelioid angiosarcoma that originated from the mandibular gingiva and resembled a dentigerous cyst on radiographs.

Case presentation: A 66-year-old Japanese man visited our hospital with a chief complaint of gingival swelling in right mandibular third molar region. A panoramic radiograph showed bone resorption around the crown of right mandibular third molar, which was impacted. Incisional biopsy confirmed a diagnosis of epithelioid angiosarcoma. The lesion exhibited aggressive proliferation after biopsy resulting in uncontrolled bleeding and difficulty in closing the mouth. Mandibular segmental resection including the tumor was performed without reconstruction. Because of the aggressive preoperative course of the tumor, the patient received adjuvant chemotherapy. There were no signs of recurrence during a 2-year follow-up period.

Conclusions: A review of the literature yielded only four reported cases of epithelioid angiosarcoma in the jaw region, with the lesions occurring in the maxilla in three cases. To our knowledge, this is the second case of primary epithelioid angiosarcoma in the mandible.
\end{abstract}

Keywords: Epithelioid angiosarcoma, Mandibular gingiva, Vascular tumor

\section{Background}

Angiosarcomas account for only $2 \%$ of all soft tissue sarcomas [1-3]. More than $50 \%$ of all cases occur in the head and neck region, with the scalp and forehead being the most common sites [4]. However, primary angiosarcomas in the oral cavity represent only $1 \%$ of all angiosarcomas [5]. Angiosarcoma generally exhibits an aggressive clinical course and an unfavorable prognosis,

\footnotetext{
* Correspondence: ikuyam@iwate-med.ac.jp

'Division of Oral and Maxillofacial Surgery, Department of Oral and

Maxillofacial Reconstructive Surgery, School of Dentistry, Iwate Medical University, 19-1 Uchimaru, Morioka, Iwate 020-8505, Japan

${ }^{2}$ Head and Neck Cancer Center, Iwate Medical University, 2-1-1 Idaidori, Yahaba-cho, Shiwa-gun, Iwate 028-3694, Japan

Full list of author information is available at the end of the article
}

even in cases where surgical removal of the tumor is possible. Affected patients usually do not benefit from chemoradiotherapy [6]. Approximately 50\% patients die within 15 months after diagnosis, and only $12 \%$ survive for 5 years or longer [7]. Generally, well-differentiated tumors have been associated with better survival rates. Tumor-related death is usually due to uncontrolled local progression and/or distant metastases to the lungs, liver, and bone $[1,8]$. Early detection and treatment are essential for controlling this highly malignant soft tissue tumor.

Epithelioid vascular neoplasm is a unique tumor characterized by proliferating "epithelioid" or "histiocytoid" endothelial cells showing a sheet-like growth pattern 
with vascular differentiation [9-11]. Epithelioid angiosarcoma (EA) is a rare variant characterized by the proliferation of atypical, large, polygonal, epithelioid endothelial cells [12].

Until now, only four cases of primary EA in the jaw region have been reported, with three lesions originating in the maxilla and one in the mandible $[2,11,13,14]$. A few cases of metastatic EA have also been reported [15-17]. To our knowledge, there is no reported case of EA involving the mandibular gingiva except pathological review of EA by Nagata et al. [2]. Here, we report a case involving an elderly man with a primary EA that originated from the mandibular gingiva and resembled a dentigerous cyst on radiographs.

\section{Case presentation}

A 66-year-old Japanese man visited a private dental office with a chief complaint of gingival swelling around right mandibular third molar. Considering the diagnosis of pericoronitis, the dentist performed incisional drainage and prescribed antibiotics and analgesics; however, the swelling reappeared with mild gingival bleeding 20 days after his first visit to the dental office. The dentist repeated incisional drainage and prescribed antibiotics, both of which were ineffective. The gingival swelling and oozing persisted; therefore, curettage of the swollen gingiva was performed. The dentist further referred the patient to our university hospital for extraction of the third molar, and he presented at our department 18 days after curettage of gingiva.

The patient's medical history included controlled hypertension and cholecystectomy for gallstones. Hematological and biochemical examinations did not reveal any abnormalities. His facial profile was symmetrical, and the submandibular lymph nodes showed no tenderness or swelling on ultrasound. Intraoral examination revealed a dark purple gingival swelling with easy bleeding around the crown of right mandibular third molar (Fig. 1a). The mass measured $1.5 \times 1.5 \mathrm{~cm}$ and covered the tooth crown. A panoramic radiograph showed that right mandibular third molar was mesially impacted, with bone resorption around the crown (Fig. 2a). Considering the clinical course of the lesion, pericoronitis was ruled out and incisional biopsy was performed under local anesthesia (Fig. 1b). The specimen was submitted for microscopic examination. Histopathological examination showed an angiosarcoma. At the time of biopsy, cone beam computed tomography (CBCT) showed mild bone consolidation (Fig. 2b) while T2-weighted magnetic resonance imaging showed high signal intensity (Fig. 2c) around the involved tooth. The region to be imaged with gadolinium was recognized; this suggested inflammation after biopsy and/or malignancy. None of the imaging studies, including fluorodeoxyglucose (FDG) positron emission tomography-computed

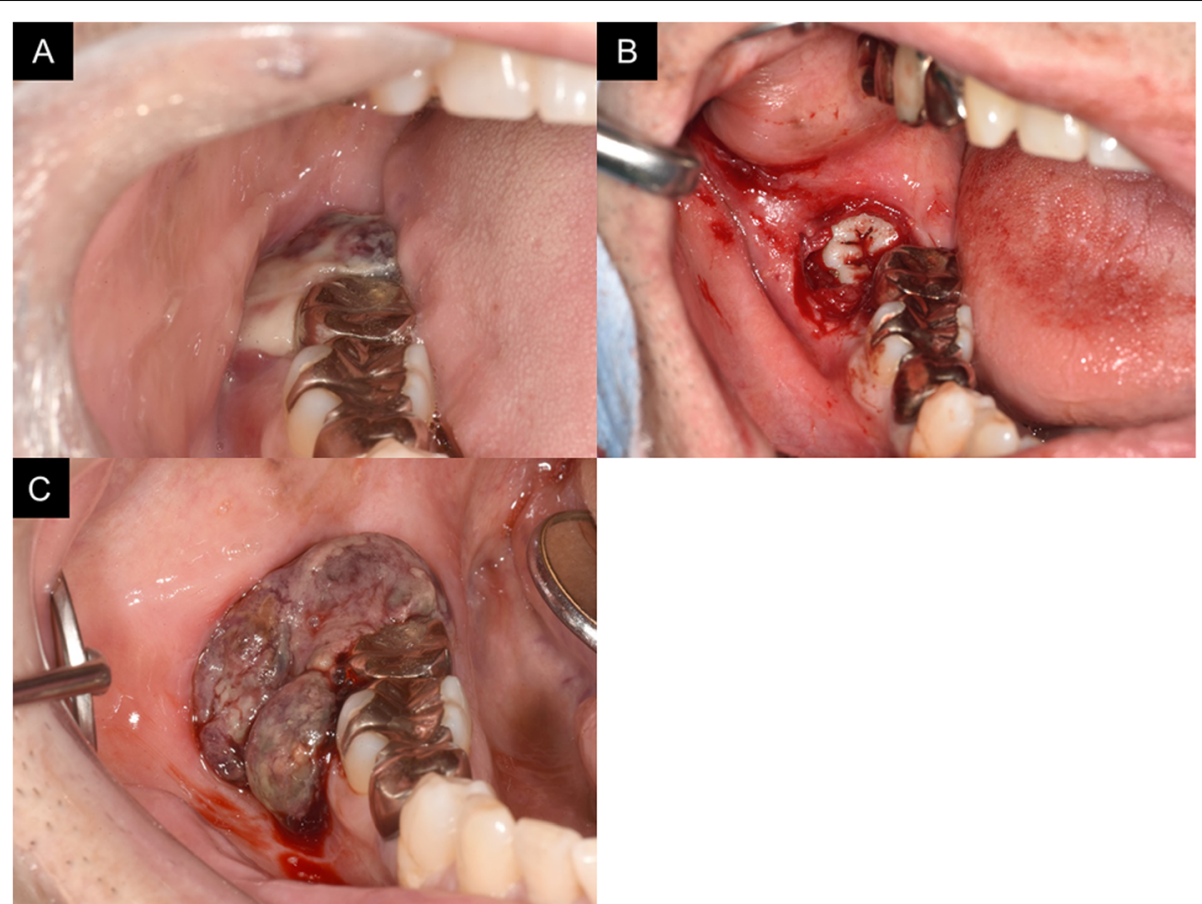

Fig. 1 Intraoral views of the patient. a His gingiva was swollen covering the crown of the right mandibular third molar at his first visit to our outpatient clinic. b The crown of right mandibular third molar after gingival biopsy. His gingiva was fragile and easy to bleed. c The enlarged lesion 4 weeks after biopsy 


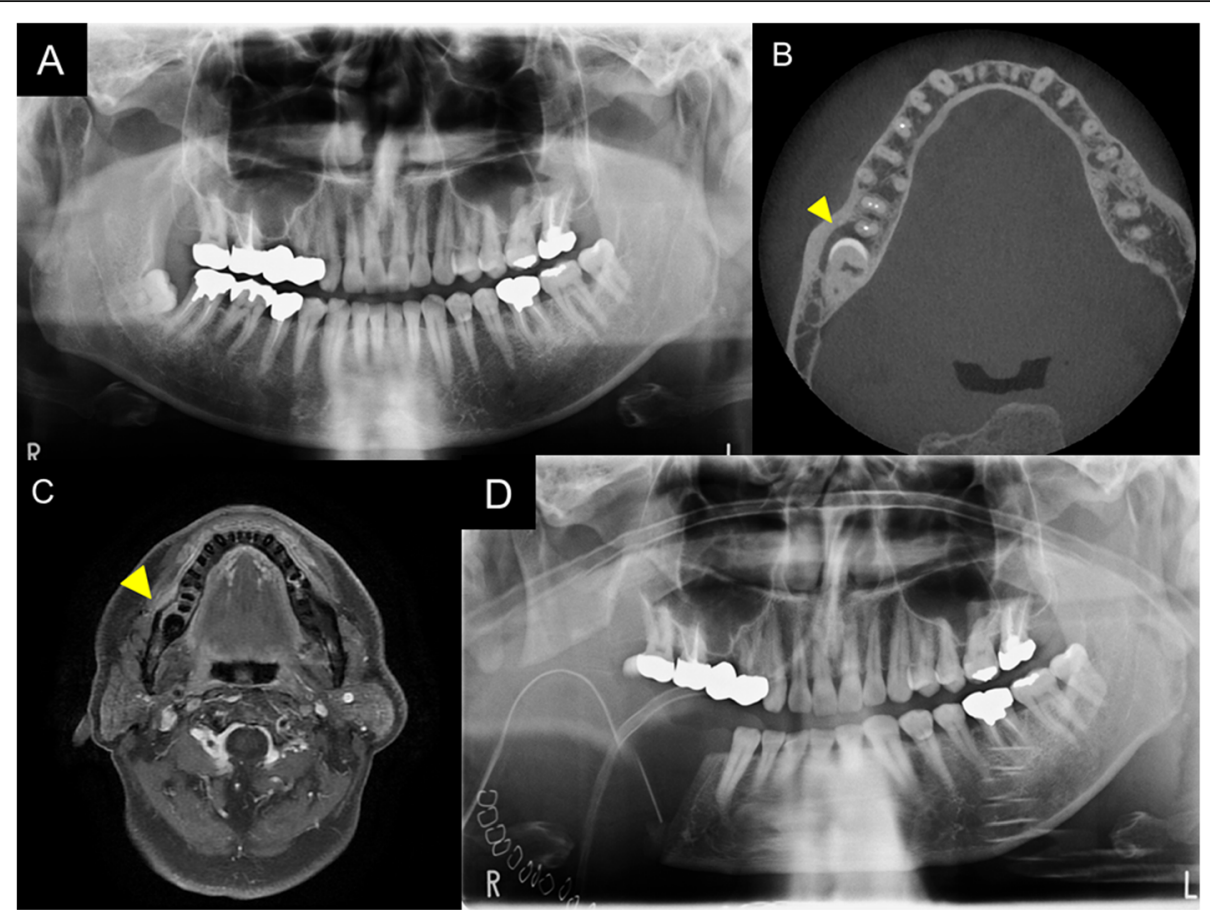

Fig. 2 Images of the patient. a Panoramic radiograph at his first visit to our outpatient clinic, showing a small cystic lesion around the embedded crown of his right mandibular third molar. The lesion resembled a hyperplastic dental sac or a dentigerous cyst. $\mathbf{b}$ Cone beam computed tomography showing the tumor with mild bone consolidation around the crown of his right mandibular third molar (arrow head). c T2-wighted magnetic resonance imaging showing high signal intensity around the crown of his right mandibular third molar (arrow head). $\mathbf{d}$ Postoperative panoramic radiograph after segmental mandibular resection

tomography, showed significant swelling of and accumulation of FDG in the cervical lymph nodes (data not shown).

Surgical treatment with vascularized free flap reconstruction was planned. However, 4 weeks after the biopsy, the lesion exhibited aggressive proliferation perhaps because of traumatic irritation by the antagonist teeth. This led to uncontrolled bleeding and difficulty in closing the mouth (Fig. 1c). The treatment plan was changed and emergent mandibular resection without surgical reconstruction was performed. An incision extending from the lower lip to the sub-mandible was made. A safety margin of $\geq 10 \mathrm{~mm}$ was set, a periosteal flap was raised, and the mandibular body was identified. Right mandibular first premolar was extracted to establish the anterior border of the resection. The sublingual gland was preserved and the tumor was resected en bloc with the oral floor membrane and buccal mucosa (Fig. 2d).

The patient's postoperative course was uneventful except for a delayed wound healing of the oral mucosa. Nevertheless, because the tumor had exhibited an aggressive preoperative course, he received adjuvant chemotherapy 2 months after the surgery [18]. Radiation therapy was deemed unnecessary. Paclitaxel $\left(80 \mathrm{mg} / \mathrm{m}^{2}\right)$ was administered once a week for 3 weeks, followed by a 1 -week rest period. This cycle was repeated for 1 year. The patient showed no signs of recurrence during the 1-year follow-up period.
Histopathologically, the tumor was composed of solid sheets with incomplete alveolar structures (Fig. 3a) and no clear vasoformation. Large, densely packed cells with spindle, oval, polygonal, or bizarre shapes could be observed. The cells exhibited abundant amphophilic cytoplasm, large vesicular nuclei, and a few prominent nucleoli. Mitotic figures were scattered throughout the tumor. Keratinization and intercellular bridges were not obvious. Immunohistochemical analysis revealed positivity for vimentin (Fig. 3b), CD31 (Fig. 3c), and factor VIII (Fig. 3d) and negativity for epithelial, neural, muscular, and other markers. The Ki67 index was $>40 \%$ (Table 1). All of above the features are diagnostic for EA.

\section{Discussion and conclusions}

EA is a rare endothelial cell malignancy. Epithelioid endothelial cell tumors include epithelioid hemangioma, epithelioid hemangioendothelioma (EHE), and EA [14]. Epithelioid hemangioma is a benign tumor while EHE is a low-grade malignancy. EA is the least common type, and it is a high-grade malignancy characterized by atypical, multilayered, or solid endothelial proliferation and a vasoformative architecture on microscopic findings. EA displays a greater degree of nuclear pleomorphism and mitotic activity than does EHE and frequently shows areas of necrosis $[19,20]$. Proposed criteria for distinguishing 


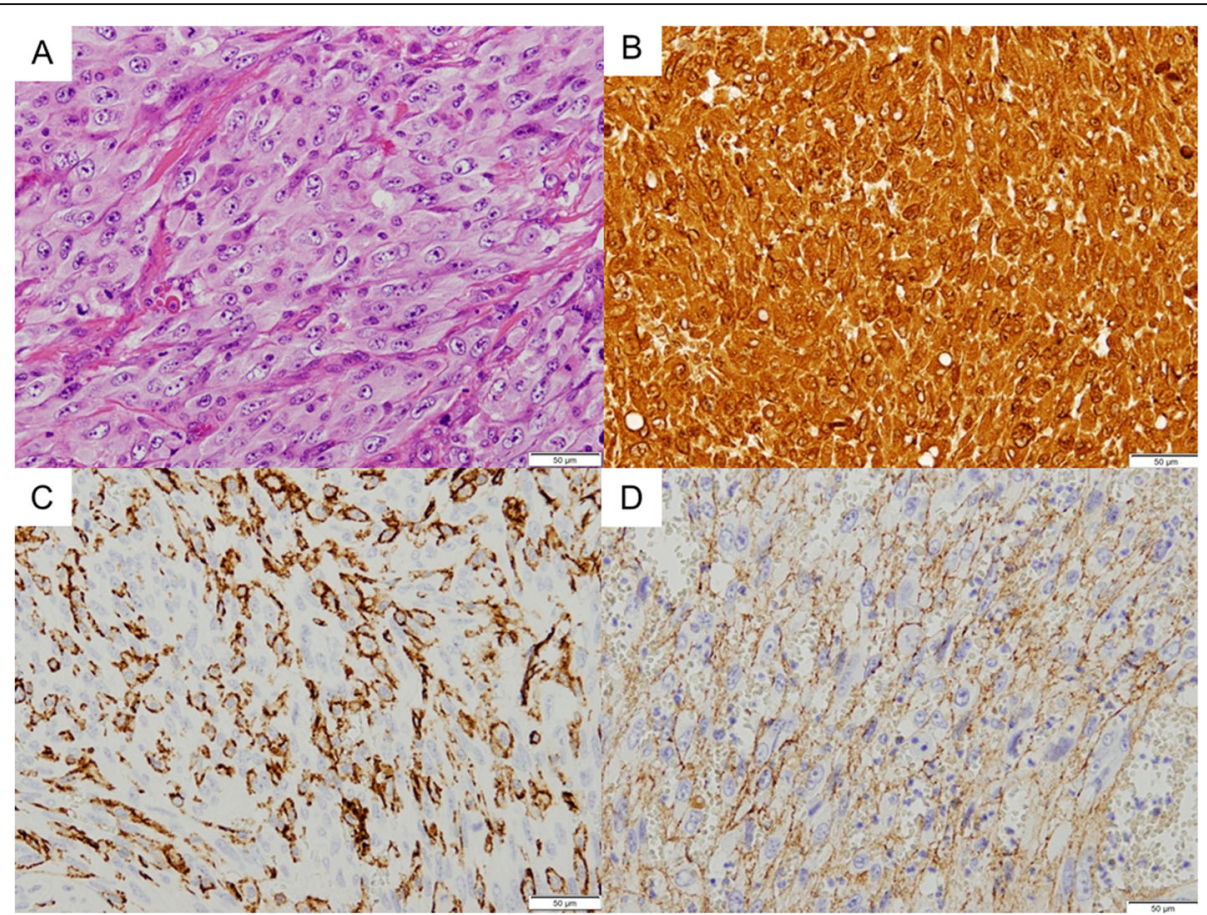

Fig. 3 Histopathological examination. a Hematoxylin and eosin staining of the specimen showed large, densely packed cells with spindle, over, polygonal, or bizarre shapes. The cells had abundant amphophilic cytoplasm, large vesicular nuclei, and a few prominent nucleoli. Mitotic figures were scattered throughout the tumor $(\times 200)$. b Immunohistochemistry findings showing positivity for vimentin in the tumor cells $(\times 200)$. c Immunohistochemistry findings showing positivity for CD31 in the tumor cells $(\times 200)$. d Immunohistochemistry findings showing positivity for factor VIII in the tumor cells $(\times 200)$

Table 1 Immunohistochemistry findings

\begin{tabular}{ll}
\hline $134 \beta E 12$ & - \\
\hline AE1AE3 & - \\
CAM5.2 & - \\
CK5/6 & - \\
P40 & - \\
P63 & - \\
EMA & - \\
E cadherin & - \\
NSE & - \\
CDK4 & - \\
$\beta$ catenin & - \\
S100 & - \\
Melan-A & - \\
Desmin & - \\
Caldesmon & - \\
CD34 & - \\
HHF35 & - \\
Vimentin & + \\
CD31 & + \\
Factor VIII & + \\
\hline
\end{tabular}

EA from other histopathological entities include a multilayered endothelium and an infiltrative growth pattern. Poorly differentiated angiosarcomas are best distinguished from other spindle cell sarcomas or carcinomas by immunohistochemistry. In particular, CD31 is the most sensitive endothelial marker [14, 19-21].

Angiosarcoma may be difficult to diagnose because of its various clinical and pathological characteristics [2]. Differential diagnoses include hemangioma, pyogenic granuloma, Kaposi's sarcoma, melanoma, and metastatic disease $[13,14,19,20]$. In the present case, primary EA of the mandibular gingiva was initially diagnosed as pericoronitis involving the mandibular third molar. In addition, CBCT suggested a hyperplastic dental follicle or a dentigerous cyst, and there were no signs of malignancy in imaging studies. Generally, radiographic findings for angiosarcoma may include osteolytic changes with a mild periosteal reaction [22]. Reviewing previous reports, it seems that the swelling of the gingiva accompanied by bone destruction with rapid growth of tumor (Table 2) [2, 11, 13-17]. In these cases, although the lesion may have originated from bone tissue, relatively well-defined margins may simulate a benign osteolytic lesion such as a cyst or an odontogenic tumor. There was a possibility that this tumor originated from bone tissue, however, the only clinical signs in the present 
Table 2 Previous reports of epithelioid angiosarcoma. Four primary epithelioid angiosarcoma in the jaw region and three cases of metastatic epithelioid angiosarcoma have been reported

\begin{tabular}{|c|c|c|c|c|c|c|}
\hline Author & Age & Sex & Primary & Metastases & Clinical oral findings & Clinical course \\
\hline Fletcher et al. 1991 [15] & 63 & M & Buttock & Aorta, maxilla & Details unknown & No evidence of disease (30 months) \\
\hline Freedman et al. 1992 [13] & 32 & M & Maxilla & - & $\begin{array}{l}\text { Painless swelling of the left side } \\
\text { of the hard palate }\end{array}$ & No evidence of disease (1.8 months) \\
\hline Sasaki et al. 1996 [11] & 69 & M & Maxilla & $\begin{array}{l}\text { Stomach, cerebrum, } \\
\text { thoracic }\end{array}$ & $\begin{array}{l}\text { Complaints of pain and swelling } \\
\text { of the left maxilla }\end{array}$ & Died of the disease ( 9 months) \\
\hline Triantafillidou et al. 2002 [14] & 50 & $\mathrm{~F}$ & Maxilla & - & $\begin{array}{l}\text { A painless swelling of the left } \\
\text { maxilla }\end{array}$ & No evidence of disease (36 months) \\
\hline Kawasaki et al. 2005 [16] & 71 & M & $\begin{array}{l}\text { Scapula, } \\
\text { Widespread }\end{array}$ & Mandible & $\begin{array}{l}\text { Painless buccal gingival swelling } \\
\text { in the left lower molar region }\end{array}$ & Died of the disease ( 1 month) \\
\hline Peacock et al. 2014 [17] & 64 & M & Kidney & Mandibular condyle & $\begin{array}{l}\text { Pain in the temporomandibular } \\
\text { joint pain, and a malocclusion }\end{array}$ & No evidence of disease (30 months) \\
\hline Nagata et al. 2014 [2] & 55 & M & Mandible & Thoracic, vertebrae & $\begin{array}{l}\text { Rapidly expanding, bluish, } \\
\text { hemorrhagic, and fragile mass }\end{array}$ & Died of the disease ( 9 months) \\
\hline Present case 2020 & 66 & M & Mandible & - & $\begin{array}{l}\text { Rapidly expanding, bluish, } \\
\text { hemorrhagic, and fragile mass }\end{array}$ & No evidence of disease (24 months) \\
\hline
\end{tabular}

case were gingival swelling and oozing, which is justified considering the origin of the tumor before osteolytic changes. The tumor enlarged rapidly after biopsy. Traumatic irritation by the antagonist teeth might accelerate the tumor growth, however, there is a possibility that this finding was due to the natural course of this rare aggressive tumor. Definitive diagnosis of angiosarcoma is challenging because of its rarity and clinical, radiographic, and histopathological resemblance to other diseases. Immunohistochemistry is generally required to identify this tumor, particularly the epithelioid and spindle cell types [2].

In immunohistochemistry, positive staining for factor VIII, CD34, and CD31, which are endothelial markers, indicates that the tumor has endothelial characteristics. The lesion in our patient showed positivity for factor VIII, CD31, and vimentin. In particular, CD31, a membrane glycoprotein that is important for endothelial cell-cell interactions and vascular adhesion of leukocytes, is considered the best marker for the endothelial phenotype, especially the poorly differentiated variant [23]. Our patient also exhibited a very high Ki67 index (>40\%).

Most authors believe that surgery in combination with radiotherapy and/or chemotherapy offers the best chance of survival [14]. Angiosarcomas exhibit a strong tendency for local recurrence and metastasis [13]. These characteristics reflect the highly aggressive nature of this tumor. Our patient received postoperative adjuvant chemotherapy because of the aggressive preoperative course of the lesion. The prognosis of angiosarcoma is unfavorable, although the tumor size and site and the histopathological grade may influence survival [24]. In particular, a poor prognosis is associated with advanced age, larger tumors, the tumor location, and a Ki67 index of $>10 \%$ [25].
Radical surgery should be performed as soon as possible for improvement of the prognosis [2].

\section{Conclusions}

We reported a rare case of a primary EA originating from the mandibular gingiva in an elderly man. To our knowledge, this is the first report of EA in the mandible, and the findings highlight the importance of early diagnosis and adequate surgical resection, which should be performed as soon as possible.

\section{Abbreviations}

EA: Epithelioid angiosarcoma; EHE: Epithelioid hemangioendothelioma; CBCT: Cone beam computed tomography; FDG: Fluorodeoxyglucose

\section{Acknowledgements \\ The authors would like to thank Editage (www.editage.jp) for English language editing.}

\section{Authors' contributions}

$\mathrm{YK}, \mathrm{YO}, \mathrm{OM}, \mathrm{HY}$, and IM reviewed the literature. $\mathrm{YO}, \mathrm{KS}, \mathrm{DS}$, and $\mathrm{KK}$ performed the operation and analyzed and interpreted the patient's data. YT performed the histopathological analyses. YK, YO, KS, DS, KK, OM, IM, and HY were clinically responsible for the patient's care. All authors have read and approved the final manuscript.

\section{Funding}

This study did not receive any funding.

\section{Availability of data and materials}

The datasets used during the current study are available from the corresponding author on reasonable request.

\section{Ethics approval and consent to participate}

This study was exempted from ethics approval by the Ethics Committee of Iwate Medical University, School of Dentistry, Morioka, Japan.

\section{Consent for publication}

The patient provided written informed consent for publication of this case report and any accompanying images. A copy of the written consent is available for review by the Editor-in-Chief of the journal. 


\section{Competing interests}

The authors declare that they have no competing interests.

\section{Author details}

'Division of Oral and Maxillofacial Surgery, Department of Oral and Maxillofacial Reconstructive Surgery, School of Dentistry, Iwate Medical University, 19-1 Uchimaru, Morioka, Iwate 020-8505, Japan. ${ }^{2}$ Head and Neck Cancer Center, Iwate Medical University, 2-1-1 Idaidori, Yahaba-cho, Shiwa-gun, Iwate 028-3694, Japan. ${ }^{3}$ Department of Head and Neck Surgery, School of Medicine, Iwate Medical University, 2-1-1 Idaidori, Yahaba-cho, Shiwa-gun, Iwate 028-3694, Japan. ${ }^{4}$ Division of Clinical Pathology, Department of Oral and Maxillofacial Reconstructive Surgery, School of Dentistry, Iwate Medical University, 2-1-1 Idaidori, Yahaba-cho, Shiwa-gun, Iwate 028-3694, Japan.

Received: 2 June 2020 Accepted: 11 August 2020

Published online: 03 October 2020

\section{References}

1. Mark RJ, Poen JC, Tran LM, Fu YS, Juillard GF. Angiosarcoma. A report of 67 patients and a review of the literature. Cancer. 1996;77:2400-6.

2. Nagata M, Yoshitake $Y$, Nakayama H, Yoshida R, Kawahara K, Nakagawa Y, et al. Angiosarcoma of the oral cavity: a clinicopathological study and a review of the literature. Int J Oral Maxillofac Surg. 2014;43:917-23.

3. Weiss SW, Antonescu CR, Deyrup AT. Angiosarcoma of soft tissue. In: Fletcher CD, et al., editors. WHO classification of tumours of soft tissue and bone. 4th ed: International Agency for Research on Cancer; 2013. p. 156-8.

4. Brad WN, Douglas DD, Carl MA, Jerry EB. Oral and maxillofacial pathology. Soft tissue tumor. Washington DC: Sanders; 2009. p. 556.

5. Fanburg-Smith JC, Furlong MA, Childers EL. Oral and salivary gland angiosarcoma: a clinicopathologic study of 29 cases. Mod Pathol. 2003;16: 263-71.

6. Favia G, Lo Muzio L, Serpico R, Maiorano E. Angiosarcoma of the head and neck with intra-oral presentation. A clinico-pathological study of four cases. Oral Oncol. 2002;38:757-62

7. Loudon JA, Billy ML, DeYoung BR, Allen CM. Angiosarcoma of the mandible: a case report and review of the literature. Oral Surg Oral Med Oral Pathol Oral Radiol Endod. 2000;89:471-6.

8. Naka N, Ohsawa M, Tomita Y, Kanno H, Uchida A, Aozasa K. Angiosarcoma in Japan. A review of 99 cases. Cancer. 1995;75:989-96.

9. Rosai J, Gold J, Landy R. The histiocytoid hemangiomas. A unifying concept embracing several previously described entities of skin, soft tissue, large vessels, bone, and heart. Hum Pathol. 1979;10:707-30.

10. Weiss SW, Enzinger FM. Epithelioid hemangioendothelioma: a vascular tumor often mistaken for a carcinoma. Cancer. 1982;50:970-81.

11. Sasaki M, Kumamoto $H$, Ooya K. An autopsy case of epithelioid angiosarcoma of the maxilla. Oral Med Pathol. 1996;1:38-42.

12. Enzinger FM, Weiss SW. Soft tissue tumors. 1st ed. St. Louis: CV Mosby; 1983. p. 422-37.

13. Freedman PD, Kerpel SM. Epithelioid angiosarcoma of the maxilla. A case report and review of the literature. Oral Surg Oral Med Oral Pathol. 1992;74: 319-25.

14. Triantafillidou K, Lazaridis N, Zaramboukas T. Epithelioid angiosarcoma of the maxillary sinus and the maxilla: a case report and review of the literature. Oral Surg Oral Med Oral Pathol Oral Radiol Endod. 2002;94:333-7.

15. Fletcher CD, Beham A, Bekir S, Clarke AM, Marley NJ. Epithelioid angiosarcoma of deep soft tissue: a distinctive tumor readily mistaken for an epithelial neoplasm. Am J Surg Pathol. 1991;15:915-24.

16. Kawasaki T, Hen K, Satoh E, Kanno H, Watanabe K, Hasegawa H. Oral presentation of epithelioid angiosarcoma with first sign in the scapula: report of a case and review of the literature. Fukushima J Med Sci. 2005;51: 77-85.

17. Peacock ZS, Lam DK, Cox DP, Schmidt BL. Metastatic epithelioid angiosarcoma to the mandible: report of a case and review of the literature. Int J Oral Maxillofac Surg. 2014;43:917-23.

18. Penel N, Bui BN, Bay JO, Cupissol D, Ray-Coquard I, Piperno-Neumann S, et al. Phase II trial of weekly paclitaxel for unresectable angiosarcoma: the ANGIOTAX study. J Clin Oncol. 2008;26:5269-74.

19. Fechner RE, Mills SE. Atlas of tumor pathology. Tumors of the bones and joints. Washington DC: Armed Forces Institute of Pathology; 1992. p. 138.
20. Kempson RL, Fletcher CD, Evans HL, Hendrickson MR, Sibley RK. Atlas of tumor pathology. Tumors of the soft tissues. Washington DC: Armed Forces Institute of Pathology; 2001. p. 353.

21. De Young BR, Wick MR, Fitzgibbon JF, Sirgi KE, Swanson PE. CD31: an immunospecific marker for endothelial differentiation in human neoplasms. Appl Immunohistochem. 1993;1:97-100.

22. Zachariades N, Papadakou A, Koundouris J, Constantinidis J, Angelopoulos AP. Primary hemangioendotheliosarcoma of the mandible: review of the literature and report of case. J Oral Surg. 1980;38:288-96.

23. Arribas-Garcia I, Domínguez MF, Alcalá-Galiano A, García AF, Valls JC, De Rasche EN. Oral primary angiosarcoma of the lower lip mucosa: report of a case in a 15-year-old boy. Head Neck. 2008;30:1384-8.

24. Holden CA, Spittle MF, Jones EW. Angiosarcoma of the face and scalp, prognosis and treatment. Cancer. 1987;59:1046-57.

25. Meis-Kindblom JM, Kindblom LG. Angiosarcoma of soft tissue: a study of 80 cases. Am J Surg Pathol. 1998;22:683-97.

\section{Publisher's Note}

Springer Nature remains neutral with regard to jurisdictional claims in published maps and institutional affiliations.
Ready to submit your research? Choose BMC and benefit from:

- fast, convenient online submission

- thorough peer review by experienced researchers in your field

- rapid publication on acceptance

- support for research data, including large and complex data types

- gold Open Access which fosters wider collaboration and increased citations

- maximum visibility for your research: over $100 \mathrm{M}$ website views per year

At BMC, research is always in progress.

Learn more biomedcentral.com/submissions 